\title{
Negociando igualdad y diferencia. Políticas y poéticas LGTBQ+ en José Infante y Txus García
}

\author{
Elena Castro \\ Louisiana State University
}

\section{Resumen}

Situado en la compleja problemática por articular otras estructuras de pensamiento no dualistas, que nos permitan ser posibles y como tales aceptados socialmente sin necesidad de que seamos asimilados al sistema normativo para conseguirlo, el presente ensayo analiza las luchas de las comunidades $L G T B Q I+$ en el Estado español y cómo estas aparecen articuladas en la producción cultural de artistas LGTBQI+ españolxs; en concreto, en la producción poética de lxs poetas José Infante (Málaga, 1946) y Txus García (Tarragona, 1974).

Palabras clave: poesía; identidad; orden normativo; dualismo de género; sujetos de sexualidades y géneros no normativos

\begin{abstract}
Located in the complex problematic of articulating other non-dualist structures of thought, which allow us to be possible and, as such, socially accepted without the need to be assimilated into the normative order to achieve it, this essay analyses the struggles of LGTBQI+ communities in Spain and how these communities are articulated in the cultural production of LGTBQI+ Spanish artists; in particular, in the poetic production of the poets José Infante (Málaga, 1946) and Txus García (Tarragona, 1974).
\end{abstract}

Key words: poetry; identity; normativity; gender binary; gender non conforming individuals

"El pensamiento de una vida posible es solo una indulgencia para aquellas personas que se saben a ellas mismas como posibles. Para aquéllas que están aún intentando ser posibles, la posibilidad es una necesidad". (Judith Butler, Mujeres y transformaciones sociales)

"Especially since the 1960 any number of Western academic, popular, and profesional discourses have been cumulatively invoking nondualistic approaches [...] But of course it's far easier to deprecate the confounding, tendentious effects of binary modes of thinking [...] that it is to articlate or model other structures of thought". (Eve Kosofsky Sedgwick, Touching Feeling) 


\section{Introducción}

En pleno siglo XXI creo imposible negar que mucho camino se ha recorrido desde que los discursos médicos del siglo XIX produjeron las identidades heterosexuales y homosexuales y los regímenes de control y ocultamiento que los perpetuaron; la realidad, sin embargo, es que hoy en día estos avances, aunque importantes, no son aún suficientes en el camino hacia la igualdad puesto que todavía hay muchas minorías — marcadas por etnia, raza, clase, género y orientación sexual- que deben luchar para que su vida sea pensada como posible.

En este ámbito de la pugna por visibilizar y erradicar las discriminaciones transversales que sufren las minorías, incluidas aquellas de sexualidades y géneros no normativos, adquieren especial relevancia en el momento presente las complejas problemáticas y tensiones que surgen de dichas luchas. En concreto, en la disputa por la igualdad que se lleva a cabo desde las comunidades LGTBQ $+{ }^{1}$, estas tensiones están centradas en cómo negociar el equilibrio entre el reconocimiento de la importancia de los derechos jurídicos y sociales ya adquiridos por las comunidades LGTBQ+ y la denuncia del peligro que dichos derechos jurídicos y sociales puede suponer para conseguir la igualdad de todas las minorías -incluidas aquellas consideradas como las más periféricas de todas ellas. Es decir, la denuncia del peligro que dichos avances pueden suponer, también dentro de las propias comunidades LGTBQ+, para conseguir el derecho a ser posibles de aquellxs que desean serlo pero desde el reconocimiento de sus diferencias, de su voluntad de articular una identidad/voz diferente, queer — como seres de sexualidades y géneros no normativos-; una identidad que sea, a un mismo tiempo, aceptada legal y socialmente y que a la vez les permita mantener su inadecuación —su condición de sujetos incómodos, queer - respecto a los modelos normativos sobre los que se estructura el orden social y el poder/estado que lo conforma, ya sean estos modelos hetero- $u$ homonormativos.

Dentro de esta compleja problemática por articular otras estructuras de pensamiento no dualistas, que nos permitan ser posibles y como tales aceptados socialmente sin necesidad de que seamos asimilados al sistema normativo para conseguirlo, el presente ensayo reflexiona sobre las luchas por los derechos de las comunidades LGTBQ+ en el marco del Estado español y cómo estas aparecen moduladas en la producción cultural de artistas LGTBQ + españolxs; en concreto, y a modo de ejemplo, este ensayo se centra en la producción poética de Ixs poetas José Infante (Málaga, 1946) y Txus García (Tarragona, 1974). Ambxs, Infante y García, en sus poemas, nombran sus identidades genéricas no normativas, desde su reconocimiento como sujetxs gay y transgénero respectivamente, y se (re)apropian de las tecnologías de control normativo para así dar espacio a una subjetividad propia, abyecta, queer, que se resiste a toda concepción de una identidad estable,

${ }^{1}$ El uso las siglas LGTBQ + (con el símbolo + al final), en lugar de las más habitua les LGTB o LGTBQI, tiene como propósito poner el énfasis en la diversidad sexual y de identidades de género, dando así mayor visibilidad, creando un espacio para la inclusión de aquellas personas y/o comunidades de prácticas sexuales e identidades genéricas consideradas como más marginales o periféricas, por situarse fuera de los sistemas normalizadores del pensamiento binario, y que no se reconocen bajo las siglas LGTBQI. 
homogénea y normativa. Para ello, y como veremos en este ensayo, ambxs se sitúan en un pensamiento no binario y a la vez que hacen visibles y denuncian los mecanismos de regulación y control del sistema binario, sobre el que se sustenta el régimen normativo que los excluye, proponen mediante sus textos poéticos, otros modos en que articular o modelar otras estructuras de pensamiento no dualista; es decir, proponen cómo articular un pensamiento sobre disidencias sexuales y génericas, no binarista, que les permita reconocerse y ser reconocidxs como seres posibles de identidades no normativas; como seres incómodos, sujetos entrometidos en la norma social.

\section{Sujetos entrometidos. Políticas y poéticas LGTBQ+ en José Infante y Txus García}

En el año 2005 se aprobó la ley por la cual se modificaba el código civil español y se legalizaba el matrimonio entre personas del mismo sexo. Solo dos años después, en 2007, se aprobó otra ley que permitía el cambio en el registro civil de la designación legal del sexo de una persona sin necesidad de someterse para ello a una operación quirúrgica. No hay duda de que la aprobación de estas dos leyes marcó un momento histórico en la lucha por los derechos legales y sociales de las comunidades LGTBQ + en el Estado español. No obstante, queda aún mucho camino por recorrer para erradicar la homofobia, la desigualdad y la discriminación de la sociedad y del código jurídico.

Como ya apunté en mi libro Poesía lesbiana queer (2014), se puede afirmar, siguiendo las ideas de Paul B. Preciado y Eve Kosofsky Sedgwick, que en el momento presente la lucha por la visibilidad, la igualdad e incluso el derecho a ser posibles —utilizando el término de Butler — va más allá de la simple denuncia de la falta de espacio para la voz o identidad gay o lesbiana. De hecho, desde que las dos leyes ya mencionadas fueran aprobadas, la lucha de las comunidades LGTBQ+ se ha desplazado hacia un más complejo sistema de marcos discursivos centrados en la negociación de una visibilidad/aceptación de estas comunidades, formuladas en términos de igualdad y diferencia, no solo por parte del sistema heteronormativo sino también par parte del hononormativismo de las propias comunidades LGTBQ+. Paul B. Preciado, siguiendo a Eve Kosofsky Sedgwick, ha analizado este cambio:

ya no se trata de desvelar un conjunto de prácticas que han estado escondidas o naturalizadas, ni de participar de las cuotas de representación, sino que nos encontramos en una situación más compleja en la que la política toma la forma, dice Sedgwick, de una "batalla entre diferentes marcos de visibilidad". ${ }^{2}$ Hemos entrado en una nueva etapa en las políticas de identidad. (Preciado, "Entrevista" 257)

Es por ello que Preciado presentó en Testo Yonqui (2008), una perspectiva crítica frente al complejo problema de los sujetos de sexualidades y/o géneros no normativos: gay, lesbiano, transgénero, etc; en el marco de su visibilidad. Preciado detalla el rol de la visibilidad en mantener los discursos

${ }^{2}$ Se refiere al texto de Eve Kosofsky Sedgwick Touching Feeling: Affect Pedagogy, Performativity. 
normativos sobre género y sexualidad y las diferentes maneras en que dichas tendencias pueden ser subvertidas. Opina que la identidad es un proceso moldeado o modelado por la visibilidad y que a su vez la excede (ibid). Se trata de la relación problemática del género, sexualidad y categorías identitarias marginales o periféricas frente a la visibilidad y aceptación social. El reto consistirá, por tanto, en negociar las condiciones de estabilidad y fluidez de las identidades. Siguiendo este planteamiento, se puede afirmar que las teorías queer no pueden operar ya sin un trabajo conjunto de estrategias hiperidentitarias antiasimilacionistas (Preciado, Testo Yonqui 25758). Estoy de acuerdo con Preciado en que "en un momento de progresiva normalización y asimilación de las minorías sexuales a la norma (matrimonio de parejas del mismo sexo, igualdad ante la ley, representación mediática, etc.) parece políticamente incongruente seguir considerando a los gays y lesbianas asimilacionistas como un activismo radical" (Preciado, Testo Yonqui 258) y hay que reconocer que estos no son una minoría. Es en esta compleja lucha por el derecho a la integración sin el peligro a la asimilación en la que colectivos como el grupo LSD (Lesbianas sin duda) o La radical gay (LRG) se centran. Como explican las activistas de LSD (lesbianas queer se llaman a sí mismas) en cita recogida por Gracia Trujillo: "Nuestra identidad sexual no la entendemos como una aséptica preferencia sexual, sino como una opción política, tal como las queer la definen: 'Yo soy queer. Yo no soy heterosexual y no quiero que mis relaciones estén legitimadas por el mundo heterosexual. Yo soy queer, yo soy diferente"" ("Sujetos y miradas" 110). Es más, en consonancia con los postulados de las teorías queer, las activistas de LSD se oponen "a las identidades fijas y homogeneizadoras" (Trujillo, "Sujetos y miradas" 113), al tiempo que defienden el carácter inestable, mutable, de toda identidad.

En diálogo con este activismo queer la poesía producida en las propias comunidades LGTBQ+ del Estado español, expone el reto por representarse, por convertirse en sujetos de su propia representación y conseguirlo sin el peligro de la asimilación al orden normativo como requisito para la aceptación. A este respecto, y al hablar del pornopoder y la necesidad de liberar la sexualidad del control biopolítico, dice Preciado: "los que hasta ahora habían sido el objetivo pasivo de la representación pornográfica ('mujeres', 'actores y actrices porno', 'putas', 'maricas y bolleras', 'perversos', etc.) aparecen ahora como los sujetos de la representación, cuestionando de este modo los códigos (estéticos, políticos, narrativos, etc.) que hacían visibles sus cuerpos y prácticas sexuales, la estabilidad de las formas de hacer sexo y las relaciones del género que estas proponen" (Preciado, Testo Yonqui 184).

Es en este contexto en el que se enmarca la apuesta poética de José Infante (Málaga, 1946) en su poemario El dardo en la llaga (2010). En el prólogo a este libro, el poeta se refiere al conjunto de este poemario como de fuerte crítica al mundo de la homosexualidad masculina e incluso habla de ortodoxia gay (11), a la que califica de tan perniciosa como la propia ortodoxia heterosexual o cualquier otra forma de intolerancia. Así por ejemplo en el "Poema 2" denuncia la homogeneización del colectivo gay al describir la típica escena de un sábado en la noche en el barrio de Chueca (Madrid), donde todo el mundo se viste igual y todos se parecen entre sí hasta el punto de no poder diferenciarlos: 
Los fines de semana aparecen de pronto.

Llevan todos idénticos peinados, camisetas,

pantalones de Armani o de Versace, algunos Prada

de última generación, y otros Cavalli o Dockers.

Han utilizado la semana completa para estudiar

esta puesta en escena que les convertirá

-esas son sus únicas pretensiones-,

al menos por una intensa noche,

en el centro de todas las miradas, [...]

(Infante 77)

Esta descripción y categorización de una masa homogénea de hombres gais que, comenta la voz poética, toma las calles de Chueca durante los fines de semana y que ha utilizado toda la semana en preparar su apariencia, su look, para ese específico momento del fin de semana y ser así el centro de atención de todas las miradas, al menos por una noche - "esas son sus únicas pretensiones", nos revela la voz poética-, se completa en los versos finales del poema con la referencia a los lugares en que esa masa homogénea de hombres gais, todos iguales, se reúnen:

\section{[...]}

en el último club de moda o en la nueva disco

que enriquece las arcas de tres o cuatro

empresarios avispados, que usan ese señuelo

juvenil para hacer caja y para propagar

la falsa idea de que los gays sólo piensan

en fiestas y en derroches, como si la felicidad

fuera eso, un sueño frívolo de fines de semana.

(Infante 77)

Parece evidente, ante este panorama de lo que, sin duda, Preciado denominaría "Queer de Luxe" ("Entrevista" 258), que la voz poética manifiesta en estos versos finales no solo cómo los discursos/identidades queer han sido vaciados de su abyección política y de la disidencia social, sexual y de género que los caracteriza - o como Preciado nos advierte en un contexto diferente, se han convertido solo en "parole, parole, parole": una palabra vacía ("'Queer"') - sino que han sido, además, absorbidos como la forma fashion y chic de la cultura gay, para convertirse en la regulación normativa de la identidad gay, y por tanto la única expresión aceptable de dicha identidad. Una identidad que queda reducida en el poema a este grupo juvenil, fiestero y frívolo que se menciona en los versos finales. La voz poética se distancia de este grupo y de la propia idea de una identidad gay homogénea y aceptada por todo el colectivo, de un modelo homonormativo de dicha identidad gay, al calificar dicha concepción de la/s identidad/es gais y su visibilidad como "falsa idea"; sugiriendo así las problemáticas de la asimilación de los colectivos LGTBQ+ a los modelos del poder normativo y al hacerlo, sugerir la posibilidad de otras identidades, otras formas de pensar y de ser gay, lesbiana, transgénero, etc. 
En el poema "Ya no quiero ser joven" la voz poética continuará distanciándose de este estereotipo gay o modelo homonormativo:

Supongo que es envidia;

ya no quiero ser joven.

No es que ahora la vida

sea más dura (la nuestra fue difícil).

Ellos tienen $-\mathrm{y}$ han tenido- ventajas,

-lo nuestro fue una carrera de obstáculos-

Dicen que son más libres ¿es eso cierto?

Viven esclavizados de su imagen,

de las modas, del cuerpo.

Son todos uniformes, libres

de no ser personales y únicos.

[...]

No. Ya no quiero ser joven.

Me aturde su belleza, sus vidas

que gritan tan sólo entorno de la noche.

Es su mundo tinieblas, soledad,

una música que repite siempre

el mismo soniquete, no tienen

más proyecto de futuro

que huir de todo lo que saben

ignorar lo que late detrás

del pensamiento. [...]

$[\ldots]$

Ellos viven mejor, pero no les envidio.

[...]

Es cansado ser joven. Y no conduce a nada.

$[\ldots]$

Supongo que es cansancio:

Ya no quiero ser joven.

(Infante 45)

Si el modo en el que nos vemos y somos vistxs se lleva a cabo mediante actos de reconocimiento e interacción social, en este poema la voz poética no puede ni quiere reconocerse con este colectivo de hombres jóvenes y guapos - "No. Ya no quiero ser joven. / Me aturde su belleza, sus vidas-, todos iguales, para los que ser gay parece quedar reducido a una cuestión estética - "Viven esclavizados de su imagen, / de las modas, del cuerpo. / Son todos uniformes, libres / de no ser personales y únicos."-, vacía de toda abyección política o conciencia social - " [...] no tienen / más proyecto de futuro / que huir de todo lo que saben / ignorar lo que late detrás / del pensamiento. 
[...]". Como ha señalado Preciado en Testo Yonqui, la visibilidad de los colectivos LGTBQ+ se produce en la intersección de prácticas mercantiles o comerciales, consumismo e incluso turismo, y al hacerlo entra en conflicto, y cambia las dimensiones de las políticas LGTBQ+. En este sentido, la visibilidad se convierte en un término conflictivo para estas comunidades, asociado a un mismo tiempo a los efectos beneficiosos y a los contrarios al propósito de conseguir la igualdad política y social. Así se puede decir que José Infante, en estos poemas, no ve la visibilidad gay como algo positivo necesariamente, sino como algo limitador y funcionando al servicio de la propia normatividad. La visibilidad está situada en un sistema de controles de la subjetividad que no se puede simplemente circunscribir al sistema binario hetero-/homonormativos; ya que como nos recuerda Judith Butler en Deshacer el género (2006) la heterosexualidad no es la única forma compulsiva u obligatoria de los mecanismos del poder que conforman la sexualidad. La propia homosexualidad también controla y restringe, como parece también afirmar aquí Infante: "Ellos tienen - $y$ han tenido - ventajas, / - lo nuestro fue una carrera de obstáculos - / Dicen que son más libres ¿es eso cierto? / [...] / Ellos viven mejor, pero no les envidio".

En el poema "Día del Orgullo Gay 2005" el sujeto poético extiende una mirada más crítica que cómplice, más cercana al Orgullo Indignado que al Día del Orgullo, ${ }^{3}$ hacia un acto tan icónico como el Día del Orgullo Gay. Este acto/celebración aparece representado en este poema como la mejor muestra de ese "Queer de Luxe" al que ya me he referido en este ensayo y al que Infante tan aguda e incisivamente critica y expone a lo largo de su poemario:

¿De qué se enorgullecen todos estos?

¿No fue el orgullo siempre una virtud

machista? En aras de la igualdad

primero hay que defenderse y conseguir

derechos, todos iguales, todos diferentes.

Con este lema que les une

acuden en manadas, cientos de miles

[...]

Se agrupan por tribus, es decir,

por carrozas. Aquí ositos, leaders

y destroyers, en aquella otra

musculocas, vigoréxicos, vegetarianos.

${ }^{3}$ El término Orgullo Indignado hace referencia a la celebración de un Día del Orgullo alternativo, concebido, desde colectivos como el COGAM, desde un pensamiento no dualista, como espacio de celebración y de denuncia, de la mercantilizacion, asimilación normativa, y vaciado de contenido del Día del Orgullo, cuya celebración, hoy más visible que nunca, paradójicamente convierte a los colectivos queer en más invisibles que nunca. El Orgullo Indignado, en su propuesta, hace presentes las tensiones entre inclusión y diferencia a la vez que recuerda a los propios colectivos LGTBQ + y a la sociedad en general el auténtico significado, activista y reivindicativo, de las fiestas del Orgullo Gay: hacer visible la diversidad de los colectivos LGTBQ + y reinvidicar el derecho de dichos colectivos a ser aceptados, a ser posibles socialmente, sin que se les exija la asimilación normativa para conseguirlo. 
También se organizan por empresas

del ramo, por saunas, por bares,

discotecas... [...]

[...]

Y todo al ritmo musical y frenético

de un carnaval fuera de fecha.

$[\ldots]$

Si el Día del Orgullo Gay se ha convertido en el símbolo por excelencia de una supuesta aceptación e integración social de los colectivos LGTBQ+ - especialmente el desfile del Día del Orgullo Gay en Madrid, el más grande de Europa-, Infante, con una incisiva mirada sobre dicho acto, cuestiona esa supuesta igualdad y aceptación social y denuncia tanto el control normativo sobre la visibilidad de las minorías, a quienes regula y categoriza, como la complacencia de dichas minorías, o gran parte de ellas, frente a tal intento de regulación y homogeneización de los colectivos LGTBQI+. Esta incisiva mirada que cruza todo el poema se hace claramente visible en versos como "todo al ritmo musical y frenético / de un carnaval fuera de fecha". En estos versos, al referirse al desfile del Día del Orgullo como un carnaval fuera de fecha, la voz poética marca el carácter de espectáculo festivo y no de evento activista y/o político de este acto. Es más, se trata de un espectáculo, sí, pero de un espectáculo grotesco/carnavalesco en el que las diferentes "manadas", como las llama la voz poética en el poema, son exhibidas, como si de un espectáculo de circo se tratara, para el entretenimiento del público asistente entre el que se encuentran desde ministros a familias, como dirá más adelante en el poema. El tono incisivo e irónico del poema le permite también a la voz poética, cuestionar, ya desde los primeros versos, la representación de este evento como una supuesta celebración de la diversidad; algo que el sujeto poético parecería defender en los versos "[...] todos iguales, todos diferentes / Con este lema que les une [...]". No obstante, rápidamente descubrimos que en realidad se trata de evidenciar la contradicción que supone presentar este acto como celebración de la diversidad cuando en realidad lo que en él se (re)presenta, y exhibe como espectáculo carnavalesco, es la homogeneización y categorización de los colectivos LGTBQ+, y los sujetos que los conforman, mediante la referencia en el poema a la agrupación de colectivos en manadas - "Con este lema que les une / acuden en manadas, cientos de miles" - que aparecen por miles y que se agrupan en tribus. Es más, estas tribus a las que se refiere la voz poética, rápidamente son identificadas en el poema como carrozas; en un guiño al lector, que no deja de mostrar, de un modo aún más evidente la falacia y la ironía, de considerar este espectáculo como un acto reivindicativo de las diferencias y visibilizando aún más su vaciado de toda disidencia social, sexual y de género : "Se agrupan por tribus, es decir / por carrozas. / Aquí ositos, leaders / y destroyers, en aquella otra / musculocas, vigoréxicos, vegetarianos. / También se organizan por empresas / del ramo, por saunas, por bares, / discotecas [...]". Así, la voz poética con esta descripción del desfile del Día del Orgullo, más que proponer una celebración de tal evento, nos sitúa en un espacio de concienciación y crítica de la categorización, ordenación y homogeneización de los colectivos LGTBQ+ por parte del orden heteronormativo; pero también del propio orden homonormativo. De hecho, este intento de control y ordenación normativa sobre las comunidades LGTBQ + se lleva a cabo a través de la imposición de una identidad gay/lesbiana esencial, fija y 
homogénea, que continúa dentro de los parámetros de un pensamiento dualista, como condición para la aceptación e integración de estos colectivos en una supuesta "normalidad" y/o integración social y protección legal. Una homonormatividad del colectivo que, parece decirnos la voz poética en este texto, es aceptada y promovida por la propia comunidad LGTBQ+, y celebrada por toda la sociedad, incluidos ministros y familias, como indica la voz poética en la estrofa final del poema:

[...] Hace muy pocos años sólo 30 o 40

personas iban por las aceras simulando

su pudor y su vergüenza, desde Santo Domingo

a la calle Preciados. Allí terminaba el paseo,

como una triste procesión de desahuciados.

Hoy ha cambiado todo. Ya no hay

por qué sentir vergüenza, humillación,

marginación en una sociedad que cambia

y crece en libertad y en igualdad

-la homofobia se oculta pero sigue

existiendo, no hay que cantar victoria.

[...]

Ahora acuden ministros,

dirigentes políticos de todas las tendencias

familias con sus hijos. Por el barrio

de Chueca en estas fiestas lo que, sin duda,

triunfa es la comprensión, la tolerancia,

el respeto a lo diferente, a pesar de negras

amenazas de los que siguen en las cloacas

de la historia y no quieren que la felicidad

sea un bien al alcance de todos.

(Infante 92-94)

Estos versos de la estrofa final, a la luz del resto del poema, no pueden sino ser entendidos como irónicos e incluso como una llamada de atención ante los peligros de confundir el avance que suponen, en la lucha por la igualdad, los logros conseguidos $-\mathrm{y}$ esa supuesta aceptación social que representa el Día del Orgullo, en su actual estructura-, con el fin de la lucha por la igualdad de todxs. De hecho, la voz poética nos recuerda en diferentes momentos, incluidos los tres versos que cierran el poema - " [...] a pesar de negras / amenazas de los que siguen en las cloacas / de la historia y no quieren que la felicidad / sea un bien al alcance de todos" (Infante 94)—, lo mucho que se ha tenido que luchar para alcanzar los derechos con los que cuenta hoy la comunidad LGTBQ + - “Hace muy pocos años sólo 30 o 40 / personas iban por las aceras simulando / su pudor y su vergüenza, / desde Santo Domingo / a la calle Preciados. / Allí terminaba el paseo, / como una triste procesión de desahuciados. / Hoy ha cambiado todo [...]" (Infante 93-94)—; así como la necesidad de mantenerse vigilantes - "la homofobia se oculta pero sigue / existiendo, no hay que 
cantar victoria" (Infante 93-94) - y, por ello mismo, el auténtico propósito de denuncia y reivindicación frente a la desigualdad con el que se creó dicho Día del Orgullo.

Si José Infante critica este asimilacionismo, mercantilización y politización (pink washing) de la identidad gay en sus poemas, si defiende de algún modo el "Gay Shame" en la época del "Gay Pride" $^{4}$ la poeta transgénero Txus García (Tarragona, 1974) va a enfocarse en un aspecto algo distinto en esta búsqueda de otras subjetividades válidas que no sean la asimilación normativista y el control de los grupos LGTBQ+ a través del consumismo y de un pensamiento dualista. Así como José Infante denuncia la imposición de un "cuerpo gay hegemónico" y la consecuente exclusión de cualquier otro cuerpo como parte de su imaginario, García, en su libro Poesía para niñas bien (2011), va más allá no solo al denunciar y rechazar una identidad y cuerpo lesbiano homogeneizados, sino al entender el propio cuerpo, y al mismo sujeto, como espacio cambiante, híbrido y mutable; un cuerpo/sujeto transgénero, según lo define Jack Halberstam en In a Queer Time \& Place (2005). Es más, Ix sujeto de este poemario es, en definitiva, una gender hacker, una pirata de género, tal como el término es formulado desde las teorías queer y sintetizado por Jorge Pérez afirmando que Ix pirata de género:

se aprovecha de las posibilidades de su cuerpo, en tanto plataforma tecnoviva que puede ser reconfigurada y de la tecnología como mediadora con la capacidad de construir sujetos híbridos [...]. El objetivo es realizar un acto de resistencia personal —cuyos efectos materiales se marcan en sus cuerpos con consecuencias teórico-discursivas-, al señalar las fallas del sistema dual de género que intenta convertir los cuerpos en esencias fijas y negar la pluralidad de los cuerpos transgénero. (Pérez 152)

Se trata, por tanto y como diría Preciado, de una transgresión de la programación de género y del colapso identitario que la acompaña. ${ }^{5}$

En la misma línea de transgresión de la programación de género, las activistas de colectivos como LSD (lesbianas sin duda) o el GtQ (Grupo de trabajo Queer) rechazan el control y regulación institucional del sexo, el género y la sexualidad con especial atención a lo que llaman "la vigilancia aduanera de los tránsitos" (Bargueiras, García y Romero (GtQ) 22) en referencia al control, por parte del discurso hegemónico y el Estado, de toda "ambigüedad de sexo, géneros y deseos" (Bargueiras, García y Romero (GtQ) 22). Es en este marco en el que se sitúa la apuesta poética de Txus García. Lx gender hacker o pirata de género aparece ya en el primer poema del libro titulado "Documento Nacional de Identidad":

${ }^{4}$ Utilizo aquí, en este juego de palabras, estos términos tal y como aparecen formulados, ya desde el propio título, en Gay Shame, editado por David. M. Halperin y Valerie Traub.

${ }^{5}$ Me refiero al uso que de este término hace Preciado en su libro Testo Yonqui. 
Aquí estoy. Me llamo Txus y soy trangénero.

Llevo siglos siéndolo.

Fui niño bollera y niña gay.

Madre me trans-vestía como una señorita:

[...]

Hice la comunión trans-vestida de blanco.

Era una pequeña y folclórica gordita.

Era marika.

Adivinad qué papel me pedía en el juego tonto ese

[de apapasyamamás...

[...]

Yo era Tarzán o Guillermo, el Travieso.

En mi bola de cristal amaba a Alaska (cuando todavía

[podía ser Olvido Gara).

Y leía Mujercitas y era Jo. Leía Los Cinco y era Jorge.

[...]

Una vez una niña me besó en un baño y me dijo que me

parecía a Superman.

Ese fue uno de los días más felices de mi vida.

Un día perfecto en Transylvania.

Desde este primer poema, que actúa a modo de declaración de principios, se nos presenta no solo una desestabilización genérica y lingüística, mediante la (con)fusión del femenino y masculino en versos como "Fui niño bollera y niña gay" o "Era una pequeña y folclórica gordita. / Era marika"; sino también una denuncia, y desestabilización de la regulación del sexo y género por parte del poder dominante y la autoridad que lo encarna (el Estado), aquí representado en el Documento Nacional de Identidad, DNI, como elemento de control y clasificación social. ${ }^{6}$ Es más, Txus García dedica los dos siguientes poemas a la misma temática de la regulación del sexo y género desde el poder/estado, mediante documentos legales, como se desprende de sus títulos, "Pasaporte" y "Visado":

${ }^{6}$ El DNI, o Documento Nacional de Identidad, es según lo define el Ministerio del Interior, que es el organismo gubernamental en España que lo emite, "un documento oficial, personal e intrasferible que acredita la identidad y los datos personales de su titular, así como la identidad española del mismo" (Ministerio del Interior). Toda persona mayor de 18 años está obligada por ley a obtener dicha tarjeta de identificación, que es el formato en que se emite este documento. En él figuran, además de una foto del/la titular, tipo pasaporte, los datos oficiales/legales, de la persona tales como nombre y apellidos, fecha de nacimiento y también el sexo de la persona según consta en el Registro Civil. 
"Pasaporte"

[...]

Era muy trans para barbilampiños machotes,

mucha chica para los maricones de armario y

demasiado camión para las tontas hetero.

Tenía tristes problemas de peluquería:

y si me corto el pelo, y si no me lo corto.

¡Eh, chico! ¿Tienes hora? Si me lo cortaba,

o ¿quién era yo? Si me lo dejaba crecer.

La solución fue peinar media melena y

de los 13 a los 21 no conocí a nadie como yo.

Estuve sola en Transylvania.

"Visado"

Crecí. A los 22 una bruja me tiró las cartas y

me dijo que conocería por fin a una chica,

[...]

Después del dolor decidí cambiar de estrategia y

me dediqué a pervertir a damas casadas,

[...]

Era una llanera solitaria, kamikaze, sex ninja,

embutida unas veces en lamé — soy marika.

Otras, vestida de cuero, como una bollera.

Desde entonces vivo in the Middlesex.

$\mathrm{Y}$, ese estar en medio como el jueves,

hace que todas tropiecen con la menda

se cuestionen sus cosillas $y$

me pregunten sobre sexo y

curioseen y

me besen casi sin querer: Yo no he sido.

Aquí estoy. Me llamo Txus.

Soy.

Al igual que hizo en "Documento Nacional de Identidad", en estos dos poemas que le siguen continúa con la desestabilización y oposición a la regulación de su identidad desde el pensamiento dualista que rige el orden normativo, presentando una contra-identidad -0 tal vez sería mejor 
llamarla disidentification, de acuerdo con el término propuesto por José Esteban Muñozi ${ }^{7}$ negándose a declararse hombre o mujer, transitando ambos géneros y situándose en un espacio propio que se encuentra a medias entre los sexos. En los tres poemas, la desestabilización genérica se produce mediante la hibridez o (con)fusión lingüística y la afirmación de que Ix sujeto poéticx no encaja en ningún espacio/categoría ya establecidas. Como dice en "Pasaporte": "Era una trans para barbilampiños machotes, / Mucha chica para los maricones de armario y / demasiado camión para las tontas hetero". Y en "Visado" afirma vivir "in the Middlesex" y termina reafirmándose en ese no pertenecer ni aceptar ser categorizada que ha desarrollado en los tres poemas; regresando para ello, en un movimiento circular, al primer verso de "Documento Nacional de Identidad" y decir ahora "Aquí estoy. Me llamo Txus. / Soy".

Como me afirmó Ix propix poeta, en este poemario se (re)presenta a unx sujeto que busca construirse a sí mismx, que busca articular una identidad disidente, de sí mismx por sí mismx; y para hacerlo transita el género, asume roles genéricos diferentes, a veces en diferentes poemas, a veces en un mismo poema, como es el caso de los poemas, "Documento Nacional de Identidad", "Pasaporte" y "Visado" a los que ya me he referido. Es por ello que en "Tits in my bowl (chamaquita)" Ix sujeto poéticx adopta el papel masculino más estereotípico, el del macho, mediante este personaje que deja salir, y al que se refiere en el poema como "este camionero who lives inside me":

"Tits in my bowl (chamaquita)"

The camionero who lives inside me me dice

que adora tus tetas, cómo se mueven,

se bambolean todo el rato, le miran,

le llaman por su nombre, iManolo!

$[\ldots]$

Esa zorra me provoca con sus tetas.

Si señorita I like you me gustas honey.

Arriba y abajo, abajo y arriba, no paran,

me incitan, me miran con su duro pezón.

y entonces, casi casi decido abandonarlo todo,

divorciarme de mi mujer, huir de lowa contigo,

comprarme una caravana y tener tres perros feos.

$[\ldots]$

${ }^{7}$ José Esteban Muñoz es quien probablemente ha aportado más que ningún otro teórico queer a la creación de este término al ofrecer esta definición del término: "Disidentification is about recycling and rethinking encoded meaning. The process of disidentification scrambles and reconstructs the encoded message of a cultural text in a fashion that both exposes the encoded message's universalizing and exclusionary machinations and recircuits its workings to account for, include, and empower minority identities and identifications. Thus, disidentification is a step further than cracking open the code of the majority; it proceeds to use this code as raw material for representing a disempowered politics or positionality that has been rendered unthinkable by the dominant culture" (31). 
Me gusta verte la cara de mala puta

que pones cuando me enseñas las tetas,

como si no hicieras nada,

como si aún fueras inocente y casta,

vestidita de blanco.

Pero las dos lo sabemos, nos lo gritamos,

que el camionero who lives inside me

hoy te abrirá su cabina, nena, de par en par.

Se trata de uno de lo textos del poemario que más claramente evidencia lo que Butler llamó gender trouble referido a la idea, luego usada por Jack Halberstam en su Masulinidad femenina (2008), de que el género es una copia carente de original. Desde el primer verso se nos invita a participar de un juego o performances, aparentemente encubierto en los versos, mediante el uso de la expresión, "who lives inside me". Ahora bien, al llegar a la estrofa final del poema todo cambia con los tres versos finales: "Pero las dos lo sabemos, nos lo gritamos / que el camionero who lives inside me / hoy te abrirá su cabina de par en par" [énfasis mío]. En el simple uso de un artículo plural femenino, recae todo el peso de la (trans)gresión que aparece en los versos de este poema. Ya que lo que de verdad se nos presenta es un performance de la masculinidad femenina, como la denominaría Halberstam. ${ }^{8}$ Pero es más que eso. Lx sujeto poéticx no solo usa este personaje masculino como tal, como una máscara, sino que lo habita ("lives inside me", dice en el poema), transita por este rol como una parte más de su propia identidad. "Manolo" no es solo una pose estética, no es una falsa imitación de la masculinidad, es una parte de quien es Ix sujeto poéticx que se nos presenta en el libro. Por otra parte, al "habitar" y encarnar, en su estereotipo, mejor que cualquier hombre biológico, el papel de la masculinidad, el poema cuestiona la masculinidad como auténtica, y nos deja entrever el modo en que esta se construye como original y, como diría Preciado, desestabiliza las diferencias entre imitado e imitador. Al hacerlo pone de manifiesto el carácter performativo de la identidad genérica y (re)presenta al género como una tecnología sofisticada de resistencia que produce cuerpos sexuales. Se manifiesta así la plasticidad del cuerpo, en su doble acepción de elástica y artificial.

Si en "Tit in my bowl" Ix pirata de género, al transitar la masculinidad a través de la identidad del camionero, evidencia las limitaciones del sistema binario, en otros poemas como "En Principium" o "...Erat Verbum", conectados entre sí, cuestiona los códigos normativos sobre el género al a sumir el rol de la "perfecta mujercita" como se la define en "En Principium" (aunque fracasa en el intento de convertirse en una). Lx voz poéticx trata, en este poema, de encajar en la cultura hegemónica, aceptando ser lo que no es: una mujer heterosexual — "En aquel tiempo / En que yo era / - pero no era" (38-39); y aunque para ello deba "fingir deseo y hambre de testosterona" (38-39) para ser así aceptada socialmente. Con este fin actúa el rol que desde el pensamiento dualista, en el que se

${ }^{8}$ El término aparece recogido en su libro Female Masculinities. 
sitúa el discurso hegemónico, se le asigna a la mujer, el de sumisión y obediencia al hombre; por eso dirá en el mismo poema que "fui una mujercita de las de verdad, / una señorita buena, / modosa, mártir y / deseosa de agradar, / inofensiva como la sopita de pollo / -me compraba hasta bragas Princesa" (38-39). Al mismo tiempo el verso "fui una mujercita de las de verdad" evidencia una vez más cómo la masculinidad, y la feminidad en este caso, son culturalmente construidas y aprendidas, o performativas; en definitiva, copias sin original. A su vez, el poema denuncia la imposición social del binarismo sexual y de género como condición para la normalidad.

No obstante, este intento de aceptación de los papeles asignados, de acceder a ser generizada por parte del discurso hegemónico como condición para la normalización, constituye en sí mismo una mascarada, ya que lo que realmente se nos está presentando es la imposibilidad de someterse a dicho rol. Es decir, Ix sujeto poéticx, (re)presenta el fracaso en su intento de convertirse en "una mujercita de las de verdad" (García 38-39) y así lo explica en "...Erat Verbum" mediante una irónica descripción de una supuesta conformidad y resignación, como indican los versos finales, ante el papel que se le ha atribuido:

Y entonces vi lo que había hecho

$Y$ vi que estaba bien y que era cómodo

Lo de vivir en un pareado con piscina,

Esperar complaciente a tu maridito,

[...]

Cambiar pañales, vomitar papillas,

[...]

Que se te llene la bañera y la cama

de santos viriles pelos negros y rizados,

Que te huela el salón a sudor macho,

[...]

Es justo

Justo y necesario,

Es nuestro deber

Y vuestra salvación.

Sin embargo, no se trata de un auténtico fracaso sino de lo que Jack Halberstam ha llamado "The Queer Art of Failure", —que podríamos traducir como el arte queer del fracaso-, para explicar las ventajas que puede tener para aquellas mujeres que no encajen en el modelo heteronormativo de mujer, el hecho de fallar como mujeres (The Queer Art of Failure 4). Así, en los poemas anteriores Ix sujeto poéticx realmente (re)presenta un "fracaso" escogido y estratégico y una proclamación de su rechazo a ser normalizada; al mismo tiempo que apuesta por la (trans)gresión de su programación de género. Txus García se apropia, en los dos poemas, de la feminidad y deconstruye su valor como identidad fija, excluyente y opresora. 
En otros poemas transita por la identidad lesbiana hegemónica desde posiciones diversas y rechaza igualmente la idea de una identidad lesbiana homogénea, fija y normativa. Así por ejemplo, en el poema "Hasta aquí puedo leer" se presenta a una lesbiana que es incapaz de decidir qué tipo de lesbiana le gusta a pesar de darnos una larga lista: "Pasivas, sedentarias e hipercalóricas, / gordas, obesas / [...] / Negras, oscuras, ocres y pardas, / latinas, chinas y no tanto, / con su buena mata de pelo / en pecho si hace falta. / [...] / Hormonadas y sin hormonas, / con polla / -de plástico, látex, carne o cristal- / y sin ella. / Masculinas, femeninas, intersex, andróginas, / [...] (García 15); para al final del poema declarar: "Ellas. / Todas. / Mierda. / Me gustan todas." (García 15). Los versos finales, "Ellas. / Todas. / Mierda. / Me gustan todas.", además de (re)presentarnos a Ix sujeto poéticx como una lesbiana que sucumbe a los encantos de todas, deconstruye la homogenización no solo de la identidad sino también del propio colectivo lesbiano y al hacerlo, y como ha indicado Gracia Trujillo, al hablar del objetivo del activismo de los grupos queer como LSD, "defiende la deconstrucción de las etiquetas identitarias como manera de cuestionar los límites excluyentes de las identidades de 'mujer', 'lesbiana' o 'gay'" (118); a la vez que "llama la atención sobre cómo las configuraciones identitarias (mujer, lesbiana o gay) con fronteras dibujadas y estables son políticamente efectivas, pero pueden crear exclusiones si sus límites no son permeables a otras diferencias" (118). Son esas otras diferencias las que Txus García hace visibles en este y otros poemas.

La producción performativa del género de la que hablan Preciado, Wittig y Butler, la propuesta de un cuerpo lesbiano queer contrahegemónico, un cuerpo trans, llega a su máximo exponente en una de las última composiciones del libro, "Fucking with 4 (polvoqueer I)". En este poema el colapso identitario que surge de la desestabilización genérica presente en los textos hasta aquí comentados se pone de manifiesto mediante un "juego de parejas" que termina revelándose no solo como juego de una sola pareja sino que, además, se trata de una pareja de lesbianas queer/trans que van asumiendo roles diferentes, bolleras y maricas a un mismo tiempo:

"Fucking with 4 (polvoqueer I)"

$[\ldots]$

Juego de parejas:

él es Toni y me vuelve loca,

ella, la tetona, es su pareja,

el otro se llama Jairo, el masajista,

yo soy su dulce novia.

Las dos llevan barbas,

pelo en el pecho,

mucha actitud,

fuerza bruta,

son tan machos...

Nos arramblan y persiguen,

[...]

nos someten con sus sexos, 
nos levantan faldas y blusitas,

[...]

y finalmente,

se dejan sodomizar

dulcemente.

$(66-67)$

En este poema, más que en ningún otro, Txus García entiende el género como una construcción, superposición y juego de máscaras y problematiza los conceptos de sexo, género, cuerpo e identidad. De hecho, es la apropiación del lenguaje hegemónico y su generización lingüística - femenino/masculino - la que es utilizada para desestabilizar las identidades genéricas y el propio pensamiento binarista sobre el que se sustenta el poder normativo. Lo que empieza pareciendo en el poema, según indican los dos primeros versos y el título, un encuentro sexual entre dos parejas, pronto se nos desvela como un interesante juego de géneros y sexualidades no normativas o desviadas — de ahí el subtitulo del poema "polvoqueer I" - en el que son "ellas" las que llevan barbas, tienen pelo en pecho y son muy machos, mientras que "ellos" se dejan sodomizar. Un juego que realmente ocurre entre una sola pareja, "las dos llevan barbas", asumiendo diferentes roles como lesbianas queer, mujeres de faldita y machos brutos y enérgicos que se dejan sodomizar; es decir "las dos" se sodomizan entre sí, en su papel de machos y maricas a un mismo tiempo. Evidencian, de este modo, que el género es una construcción cultural, aprendida en su constante repetición. No se trata, sin embargo, de un simple juego de disfraces, en los que se intercambian ropa y accesorios de hombre y de mujer, sino de evidenciar, como ha comentado Trujillo en otro contexto, que "la relación entre sexo y género es performativa" ("Desde los márgenes" 38). Por tanto, podemos afirmar, como demostró Butler en El género en disputa (2007), que esos actos performativos, esas parodias, son realmente "actos corporales subversivos" (Trujillo, "Desde los márgenes" 38).

Por su parte, Preciado ha comentado que las parodias de género producen distorsiones en los códigos de significación dominante; es más, para Preciado "lo que la crítica transgenérica ha puesto sobre la mesa no son ya performances, sino transformaciones corporales físicas, sexuales, sociales y políticas que ocurren no en el escenario, sino en el espacio público" ("Entrevista" 249). Se da así entrada en el poema a otras posibles manifestaciones de materialidad corporal que exceden los límites de los regímenes que determinan qué cuerpos y qué sujetos son posibles y en qué condiciones.

En el activismo de los grupos de prácticas genéricas y sexualidades no normativas cobra especial relevancia el reto por representarse, por convertirse en sujetos de su propia representación, por articular su propia identidad desde un pensamiento no dualista que les permita ser posibles. Es en este contexto en el que cobra sentido la apuesta poética de Txus García. Como afirma Ix propia poetx, en sus textos va de lo personal a lo político y al darse visibilidad, al desreconocerse o desidentificarse en sus poemas, se resiste a asumir la homogeneización del colectivo lesbiano, o el de toda la comunidad LGTBQ+, como condición para la aceptación social. Como García afirmó en 
la entrevista que me concedió en 2012: "Yo escribo lo que soy", "no se puede separar la poesía de lo que soy". La inestabilidad en la identidad genérica, conseguida mediante este transitar el género del que Txus García habla, le permite (re)presentar una subjetividad propia que está situada dentro de las culturas de resistencia a la identidad, sexualidad, y generización normativas, sean estas homo- o heteronormativas.

Si para Preciado las teorías queer "denuncian las exclusiones, los fallos de la representación y los efectos de renaturalización de toda política de identidad" ("Entrevistas" 247), en esta misma línea se puede afirmar que en Ix pirata de género que surge de los poemas de Txus García en su tránsito por identidades y géneros varios, trans, lesbiana queer, masculinidad, feminidad, etc; hay un claro intento de negar la naturalización de una identidad heterosexual hegemónica, pero también de una supuesta identidad contrahegemónica, homogeneizadora de todo el colectivo LGTBQI+. Denuncia, en definitiva, la exclusión de las minorías periféricas; reclama un espacio para ellas a la vez que proclama la mutabilidad, hibridez e inestabilidad de toda identidad de género, proclamándose unx pirata de género que no reside en ninguna y a la vez reside en todas, en un espacio de sexualidades y géneros imposibles de calificar. Se sitúa así en un espacio surgido desde un pensamiento no dualista y hace una apuesta poética de cómo pensar el mundo, y a sí mismx, desde otro lugar, desde un mundo postbinarismo, postgénero.

A través de sus poemarios, tanto José Infante como Txus García entrometen a los sujetos que aparecen en sus versos en la cuota de visibilidad que el discurso normativo está dispuesto a conceder al colectivo LGTBQ $+y$, en consonancia con el activismo político y social que los grupos queer llevan a cabo, denuncian la exclusión de las minorías periféricas; reclaman, en definitiva, el derecho a ser posibles como sujetos inadecuados, queer.

En ambxs hay un claro intento de desmantelar la naturalización de una supuesta contraidentidad gay/lesbiana esencial y fija y el pensamiento dualista que la sustenta. Infante y García articulan en sus textos una apuesta de disidentification sobre los discursos de homogenización del colectivo gay/lesbiana que se imponen desde el poder/Estado normativo y desde el control homonormativo del propio colectivo LGTBQ+.

\section{Referencias bibliográficas}

Bargueiras Martínez, Carlos, Silvia García Dauder y Carmen Romero Bachiller, GtQ (Grupo de trabajo Queer). "Introducción. El eje del mal es heterosexual". El eje del mal es heterosexual. Figuraciones, movimientos y prácticas feministas "queer". Eds. GtQ. Madrid: Traficantes de Sueños, 2005. 17-29. Web. 11 jun. 2017 <https://goo.gl/FWtBQW>.

Butler, Judith. Deshacer el género. Trad. Patrícia Soley-Beltran. Barcelona: Paidós, 2006. Impreso. 
El género en disputa. El feminismo y la subversión de la identidad. Trad. María Antonia Muñoz. Barcelona: Paidós, 2007. Impreso.

"La cuestión de la transformación social". Mujeres y transformaciones sociales. Eds. Elisabeth Beck-Gernsheim, Judith Butler y Lidia Puigvert. Barcelona: El Roure, 2001. 7-30. Impreso.

Castro, Elena. Poesía lesbiana queer. Cuerpos y sujetos inadecuados. Barcelona: Icaria, 2014. Impreso.

García, Txus. Poesía para niñas bien. Tits in my bowl. Barcelona: Cangrejo pistolero, 2011. Impreso.

Halberstam, Judith [Jack]. In a Queer Time \& Place. Transgender Bodies. Subcultural Lives. London: New York UP, 2005. Impreso.

-------. Masculinidad femenina. Trad. Javier Sáez. Barcelona: Egales, 2008. Impreso

The Queer Art of Failure. Durham: Duke UP, 2011. Impreso.

Halperin, David. M. y Valerie Traub, eds. Gay Shame. Chicago: U of Chicago P, 2009. Impreso.

Infante, José. El dardo en la llaga. (Poemas porno satíricos). Madrid: Ediciones Vitruvio, 2010. Impreso.

Kosofsky Sedgwick, Eve. Touching Feelings. Affect, Pedagogy, Performativity. Durham: Duke UP, 2003. Impreso.

Ministerio del Interior (Gobierno de España). Web. 25 mayo $2017<$ https://goo.gl/o3pgsD>.

Muñoz, José Esteban. Disidentifications: Queers of Color and the Performance of Politics. Minneapolis: U of Minnesota P, 1999. Impreso.

Pérez, Jorge. "Pensamientos y no solo acción: sobre la valiosa aportación peninsular a la Teoría Queer". Un espacio queer-Queer Space. Eds. Kay Sibbald y Rosalía Cornejo Parriego. Número especial de Revista Canadiense de Estudios Hispánicos 35.1 (2010): 141-61. Impreso.

Preciado, Beatriz. "Entrevista a Beatriz Preciado, por Jesús Carrillo". Desacuerdos 2 (2005): 243-61. Web. 11 jun 2017 <https://goo.gl/Arl5jO>.

. "Queer': Historia de una palabra". Parole de queer. 2012. Web. 11 jun. 2017

$<$ https://goo.gl/OY6f1Q>.

------. Testo Yonqui. Madrid: Espasa Calpes, 2008. Impreso.

Trujillo, Gracia. "Desde los márgenes. Prácticas y representaciones de los grupos queer en el Estado español". El eje del mal es heterosexual. Figuraciones, movimientos y prácticas feministas "queer". Eds. GtQ (Grupo de trabajo Queer). Madrid: Traficantes de Sueños, 2005. 29-45. Web. 11 jun. 2017 <https://goo.gl/FWtBQW>.

. "Sujetos y miradas inapropiables/adas. El discurso de las lesbianas Queer". Lesbianas: discursos y representaciones. Ed. Raquel Platero. Madrid: Melusina, 2008, 107-18. Impreso 